\title{
Analysis of adult 20-year survivors after liver transplantation
}

\author{
C. Dopazo • I. Bilbao • L. L. Castells • G. Sapisochin • \\ C. Moreiras $\cdot$ I. Campos-Varela $\cdot$ J. Echeverri $\cdot$ \\ M. Caralt $\cdot$ J. L. Lázaro $\cdot$ R. Charco
}

Received: 24 March 2014/ Accepted: 21 August 2014/Published online: 18 September 2014

(C) Asian Pacific Association for the Study of the Liver 2014

\begin{abstract}
Background Liver transplantation (LT) is the treatment of choice for chronic and acute liver failure; however, the status of long-term survivors and allograft function is not well known.

Aim To evaluate the clinical outcome and allograft function of survivors 20 years post-LT, cause of death during the same period and risk factors of mortality.

Methods A retrospective study was conducted from prospective, longitudinal data collected at a single center of adult LT recipients surviving 20 years. A comparative subanalysis was made with patients who were not alive 20 years post-transplantation to identify the causes of death and risk factors of mortality.

Results Between 1988 and 1994, 132 patients received 151 deceased-donors LT and $28(21 \%)$ survived more than 20 years. Regarding liver function in this group, medians of AST, ALT and total bilirubin at 20 years post-LT were $33 \mathrm{IU} / \mathrm{L}$ (13-135 IU/L), 27 (11-152 IU/L) and $0.6 \mathrm{mg} / \mathrm{dL}$ $(0.3-1.1 \mathrm{mg} / \mathrm{dL})$. Renal dysfunction was observed in $40 \%$ of patients and median eGFR among 20-year survivors was $64 \mathrm{~mL} / \mathrm{min} / 1.73 \mathrm{~m}^{2}\left(6-144 \mathrm{~mL} / \mathrm{min} / 1.73 \mathrm{~m}^{2}\right)$. Sixty-one percent of 20-year survivors had arterial hypertension,
\end{abstract}

C. Dopazo $(\bowtie) \cdot$ I. Bilbao · G. Sapisochin · C. Moreiras ·

J. Echeverri · M. Caralt · J. L. Lázaro · R. Charco

Department of HBP Surgery and Transplants, Hospital

Universitario Vall d́Hebron, Universidad Autónoma de

Barcelona, Paseo Vall d́Hebron 119-129, 08035 Barcelona,

Spain

e-mail: cdopazo@vhebron.net

L. L. Castells - I. Campos-Varela

Hepatology Unit, Department of Internal Medicine, Hospital

Vall d́Hebron, CIBERehd, Universidad Autonoma de Barcelona,

Barcelona, Spain
$43 \%$ dyslipidemia, $25 \%$ de novo tumors and $21 \%$ diabetes mellitus. Infections were the main cause of death during the 1st year post-transplant (32\%) and between the 1 st and 5th year post-transplant $(25 \%)$. After 5th year from transplant, hepatitis $\mathrm{C}$ recurrence $(22 \%)$ became the first cause of death. Factors having an impact on long-term patient survival were HCC indication $(p=0.049)$, pretransplant renal dysfunction $(p=0.043)$ and long warm ischemia time $(p=0.016)$; furthermore, post-transplant factors were diabetes mellitus $(p=0.001)$ and liver dysfunction $(p=0.05)$ at 1 year.

Conclusion Our results showed the effect of immunosuppression used during decades on long-term outcome in our LT patients in terms of morbidity (arterial hypertension, diabetes mellitus, dyslipidemia and renal dysfunction) and mortality (infections and hepatitis $\mathrm{C}$ recurrence).

Keywords Liver transplantation - Long-term outcome · Immunosuppression $\cdot$ Risk factors

\section{Introduction}

The aims of liver transplantation (LT) are to increase survival and quality of life in patients with acute liver disease, end-stage chronic liver disease with or without early hepatocellular carcinoma (HCC), and those with certain metabolic diseases affecting the liver or other organs. Over the past 20 years since LT became an established procedure, progress has been impressive [1-4]. The current databases of the European [5] and American Liver Transplant Registries [6] show 1-year and 10-year survival rates of over 90 and $60 \%$, respectively, clearly higher than expected survival if the disease was allowed to run its clinical course. 
Although several centers are now reaching 20 years of clinical experience with LT, little information on actual 20-year survival in adult liver transplant patients exists in the literature [7-9]. With many more patients receiving transplants in the 1990s than in the 1980s, and after overcoming the learning curve concerning improvements in surgical techniques, immunosuppression regimens and management of infections, the transplant community can expect a considerable increase in the total number of 20-year LT survivors over the next decade.

The aims of the present study were to retrospectively analyze the clinical outcome of LT survivors followed up for at least 20 years. More specifically, we aimed to determine the incidence of chronic renal dysfunction, arterial hypertension, diabetes mellitus, dyslipidemia, cardiovascular events and de novo tumors. The causes of death during the same period and risk factors of mortality were also analyzed.

\section{Patients and methods}

Study design

A retrospective analysis of prospective, longitudinal data, collected at a single center was performed to evaluate 20-year LT survivors. The study group consisted of all adult patients ( $>18$ years of age) who underwent LT at the Hospital Vall d́Hebron (Barcelona, Spain) between October 1988 and May 1993 with a minimum survival of 20 years post-transplantation. A comparative sub-analysis was performed with patients not alive 20 years after transplantation to identify the causes of death and risk factors of mortality. Median follow-up was 59 months with a range of 0-292 months.

During study period, a Collins solution was used for graft preservation until 1990, and thereafter the University of Wisconsin (UW) in all cases. Bypass or the classical technique was standard until 1991 when it was switched to inferior vena cava preservation in the anhepatic phase. Maintenance immunosuppression regimens consisted of a double regimen of cyclosporine (CyA) and prednisone or a triple-drug regimen that included azathioprine from 1988 to 1995 . The routine use of tacrolimus was initiated at our institution in 1993, and it has become the standard maintenance immunosuppressive agent.

Pre-transplant demographic characteristics of recipients, donors, surgery and all post-transplant events and complications during follow-up were analyzed. Recipient characteristics analyzed were: age, sex, indications for transplant, serology, Child-Pugh class, United Network for Organ Sharing (UNOS) status, concomitant diseases (renal dysfunction, arterial hypertension, diabetes mellitus and cardiovascular disease) and primary or retransplantation.

Regarding donor characteristics, we should specify that all of them were deceased donor after brain death. Main donor data studied were: age, gender, cause of death and hepatic steatosis. Surgical variables analyzed were: cold ischemia time (CIT) and warm ischemia time (WIT), presence of portal thrombosis, and intraoperative transfusion.

All post-operative complications arising during followup were entered prospectively in a database. Medium- and long-term variables evaluated at different time points $(1 \mathrm{st}$, 5th, 10th, 15th and 20th year) were: renal and liver function, incidence of arterial hypertension, diabetes mellitus, dyslipidemia, cardiovascular events, and de novo malignancies.

\section{Definitions}

CIT was defined as time from cross-clamping until removal of the organ from the ice to implantation commences, and WIT as time of ischemia during graft implantation.

Primary graft dysfunction was defined as poor initial graft function, leading to retransplantation or death during the first week post-transplant. Graft dysfunction was classified according to the highest peak of liver function test during the first 4 days post-transplant [4]: mild (transaminases $<1,000$ IU and prothrombin index $>60 \%$ ), moderate (transaminases 1,000-5,000 IU and prothrombin index $30-60 \%$ ) and severe (transaminases $>5,000$ IU and prothrombin index $<30 \%$ ).

Patients were monitored at outpatient clinics and laboratory data were evaluated monthly for the first 3 months and every 3 or 6 months thereafter. Based on laboratory results, we defined post-transplant liver dysfunction as AST/ALT $\geq 100 \mathrm{IU} / \mathrm{L}$ and/or total bilirubin $\geq 1.5 \mathrm{mg} / \mathrm{dL}$, requiring complete study with Doppler ultrasound and liver biopsy according to our protocol.

Rejection episodes were determined by liver biopsy and graft rejection defined and stratified according to the BANFF criteria [10]; cytomegalovirus (CMV) infection was diagnosed when viral load exceeded 1,000 copies/mL.

$\mathrm{HCV}$ recurrence was diagnosed by liver biopsy in patients with liver dysfunction and who were HCV-RNApositive, and no protocol liver biopsies were available as no standardized procedure was in place in our follow-up at that time.

Renal function was evaluated by serum creatinine levels and estimated glomerular filtration rate (eGFR) by the Modification of Diet in Renal Disease (MDRD)-4 formula. Renal dysfunction was defined as eGFR $<60 \mathrm{~mL} / \mathrm{min} /$ $1.73 \mathrm{~m}^{2}$ [11]. However, since eGFR data were not always available in our study at that time, pre-transplant renal 
dysfunction was defined as pre-transplant creatinine levels $\geq 1.5 \mathrm{mg} / \mathrm{dL}$ hepato-renal syndrome or need for dialysis.

The following definitions were applied for the main risk factors of cardiovascular disease:

1. Arterial hypertension. Defined as blood pressure $>140$ / $90 \mathrm{mmHg}$ at two following visits according to the European Society of Hypertension criteria [12].

2. Diabetes mellitus. Defined as fasting plasma glucose $>126 \mathrm{mg} / \mathrm{dL}$ at two following visits according to the World Health Organization [13].

3. Dyslipidemia. Defined as hypercholesterolemia $>220 \mathrm{mg} / \mathrm{dL}$ and hypertriglyceridemia $>200 \mathrm{mg} / \mathrm{dL}$ at two following visits.

\section{Statistical analysis}

Statistical analysis was performed using SPSS 21.0 software (SPSS, Chicago, IL, USA). Quantitative variables normally distributed were expressed as mean values $\pm 1 \mathrm{SD}$ and those non-normally distributed were expressed as median values (range). Qualitative variables were expressed as proportions. Group comparisons were made by Student's $t$ test and Mann-Whitney $U$ test for continuous data and the Chi square test with Fisher's correction for categorical data. Differences were considered statistically significant when the $p$ value was $<0.05$. Survival curves were analyzed using Kaplan-Meier curves. Cox regression was used to assess independent factors associated with overall survival, and deaths in the first year post-transplant were excluded to assess the independent factors associated with long-term survival ( $>1$ year posttransplant).

\section{Results}

Study population

Between 1988 and 1994, 132 patients received 151 orthotopic LT at our center. Twenty-eight of the 132 patients have survived for more than 20 years and comprise the study group.

The primary indications for transplantation are shown in Table 1. The most common indication in the 20-year survivors was HCV cirrhosis, followed by cholestatic cirrhosis
Table 1 Pre-transplant recipient characteristics
UNOS United Network for Organ Sharing

\begin{tabular}{|c|c|c|c|}
\hline & $\begin{array}{l}20 \text {-year survivors } \\
(n=28)\end{array}$ & $\begin{array}{l}\text { Non-20-year survivors } \\
(n=104)\end{array}$ & $p$ \\
\hline Age (years) & $54(24-66)$ & $55(16-66)$ & 0.13 \\
\hline Gender (male/female) & $16(57 \%) / 12(43 \%)$ & $71(68 \%) / 33(32 \%)$ & 0.93 \\
\hline Etiology of liver disease & & & 0.04 \\
\hline HCV cirrhosis & $10(36 \%)$ & $35(34 \%)$ & \\
\hline Alcoholic cirrhosis & $4(14 \%)$ & $26(24 \%)$ & \\
\hline Hepatocellular carcinoma & $2(7 \%)$ & $23(22 \%)$ & \\
\hline Cholestatic cirrhosis & $7(25 \%)$ & $5(5 \%)$ & \\
\hline Fulminant failure & $2(7 \%)$ & $6(6 \%)$ & \\
\hline Metabolic cirrhosis & - & $1(1 \%)$ & \\
\hline Budd Chiari & - & $1(1 \%)$ & \\
\hline Others & $3(10 \%)$ & $7(7 \%)$ & \\
\hline ABO identical & $25(89 \%)$ & $99(95 \%)$ & 0.24 \\
\hline Child-Pugh class & & & 0.66 \\
\hline A & $4(14 \%)$ & $10(10 \%)$ & \\
\hline B & $11(40 \%)$ & $37(35 \%)$ & \\
\hline $\mathrm{C}$ & $13(46 \%)$ & $57(55 \%)$ & \\
\hline UNOS status & & & 0.87 \\
\hline Home & $24(86 \%)$ & $92(88 \%)$ & \\
\hline Hospital & $1(4 \%)$ & $4(4 \%)$ & \\
\hline Intensive Care & $3(10 \%)$ & $8(8 \%)$ & \\
\hline Urgent liver transplant & $2(7 \%)$ & $7(7 \%)$ & 0.93 \\
\hline Renal dysfunction & $1(4 \%)$ & $13(13 \%)$ & 0.17 \\
\hline Hypertension & $1(4 \%)$ & $6(6 \%)$ & 0.93 \\
\hline Diabetes mellitus & $3(11 \%)$ & $12(12 \%)$ & 0.90 \\
\hline Cardiovascular disease & $3(11 \%)$ & $10(10 \%)$ & 0.86 \\
\hline
\end{tabular}


Table 2 Donor and surgery characteristics

\begin{tabular}{llll}
\hline & $\begin{array}{l}20 \text {-year survivors } \\
(n=28)\end{array}$ & $\begin{array}{l}\text { Non-20-year survivors } \\
(n=104)\end{array}$ & $p$ \\
\hline Age (years) & $37(9-64)$ & $32(7-64)$ & 0.59 \\
Gender (male/female) & $20(72 \%) / 8(28 \%)$ & $67(65 \%) / 37(35 \%)$ & 0.48 \\
Cause of death & & & 0.60 \\
Cerebrovascular accident & $14(50 \%)$ & $46(44 \%)$ & \\
Cranio-encephalic trauma & $9(32 \%)$ & $44(42 \%)$ & \\
Anoxia & $3(11 \%)$ & $5(5 \%)$ & 0.06 \\
Others & $2(7 \%)$ & $9(9 \%)$ & 0.07 \\
Graft steatosis $>20 \%$ & $2(7 \%)$ & $24(23 \%)$ & 0.45 \\
Cold ischemia time (min) & $528 \pm 155$ & $504 \pm 153$ & 0.05 \\
Warm ischemia time (min) & $61 \pm 20$ & $70 \pm 23$ & \\
Portal thrombosis & $1(4 \%)$ & $19(18 \%)$ & 0.006 \\
Intraoperative transfusion & & $8(2-75)$ & 0.17 \\
Red blood cells (unit) & $6(2-22)$ & $12(3-75)$ & 0.03 \\
Fresh frozen plasma (unit) & $11(3-28)$ & $10(0-54)$ & \\
Platelets (unit) & $5(0-30)$ & &
\end{tabular}

(primary and secondary biliary cirrhosis and primary sclerosing cholangitis). Alcoholic cirrhosis and HCC were less frequent indications in 20-year survivors than in nonsurvivors. Pre-transplant recipient characteristics, donor and surgery data are shown in Tables 1 and 2 .

Regarding the main post-operative complications (Table 3), recipients surviving 20 years had a lesser tendency to CMV infection (21 vs. $34 \%, p=0.15$ ) and biopsy-proven acute rejection ( 54 vs. $65 \%, p=0.25$ ) than non-survivors. Moreover, progression to chronic rejection was slightly significantly lower in 20-year survivors compared to non-survivors ( 7 vs. $22 \%, p=0.06$ ). No vascular complications occurred in 20-year survivors and biliary complications were similar in both groups (21 vs. $25 \%$, $p=0.69)$. At 1 year post-transplant, renal dysfunction had been present in $50 \%$ of patients who survived for 20 years (vs. $67 \%, p=0.21$ ) and liver dysfunction in $18 \%$ (vs. $45 \%, p=0.01)$.

Long-term complications in 20-year survivors (Table 4)

Regarding liver function, medians of AST, ALT and total bilirubin at 20 years were 33 IU/L (13-135 IU/L), 27 (11-152 IU/L) and $0.6 \mathrm{mg} / \mathrm{dL}(0.3-1.1 \mathrm{mg} / \mathrm{dL})$, respectively. Two patients $(7 \%)$ with the diagnosis of cirrhotic stage secondary to hepatitis $\mathrm{C}$ recurrence presented liver dysfunction at that time.

Renal function remained stable during the 20-year follow-up and median eGFR at 20 years was $64 \mathrm{~mL} / \mathrm{min} /$ $1.73 \mathrm{~m}^{2}\left(6-144 \mathrm{~mL} / \mathrm{min} / 1.73 \mathrm{~m}^{2}\right)$. Ten patients $(40 \%)$ presented renal dysfunction at that time, and only 1 (4\%) developed chronic kidney failure requiring hemodialysis.

Development over time of the different risk factors known to be associated with cardiovascular disease, including arterial hypertension, diabetes mellitus and dyslipidemia, is shown in Table 4. In summary, at 20 years post-transplant, $61 \%$ had arterial hypertension (72\% were managed with one medication), $21 \%$ diabetes mellitus (50\% with oral antidiabetics, $40 \%$ with insulin and $10 \%$ with diet) and $43 \%$ dyslipidemia $(75 \%$ requiring medication). Five patients (18\%) developed some cardiovascular event during follow-up: ischemic cardiomyopathy in 2, atrial fibrillation in 2 and peripheral vascular disease in 1 .

Seven patients $(25 \%)$ developed de novo tumors: prostate cancer in two patients, laryngeal carcinoma in one, melanoma in one, basal cell carcinoma of the skin in two and squamous cell carcinoma of the skin in one. Four patients developed a second de novo tumor, all skin cancers (basal cell carcinoma in three patients and squamous cell carcinoma in one).

After 20 years of survival, $53 \%$ of the patients remained on anticalcineurin inhibitors in monotherapy, and in only three patients (11\%) could immunosuppression be withdrawn definitively.

Patient and graft survival

Overall actuarial 5-, 10- and 20-year patient survival rates were 48, 38 and $22 \%$, and graft survival rates 43, 32 and $20 \%$, respectively. The survival range among 20-year 
Table 3 Induction immunosuppression and main post-operative complications

\begin{tabular}{|c|c|c|c|}
\hline & $\begin{array}{l}\text { 20-year } \\
\text { survivors } \\
(n=28)\end{array}$ & $\begin{array}{l}\text { Non-20-year } \\
\text { survivors } \\
(n=104)\end{array}$ & $p$ \\
\hline Induction immunosuppression & & & 0.61 \\
\hline CyA-St & $22(78 \%)$ & $73(72 \%)$ & \\
\hline Tac-St & $6(22 \%)$ & $19(19 \%)$ & \\
\hline Cya-St-AZA & - & $7(7 \%)$ & \\
\hline St-OKT3 & - & $2(2 \%)$ & \\
\hline Ischemia reperfusion injury & & & 0.32 \\
\hline Mild & $13(47 \%)$ & $67(65 \%)$ & \\
\hline Moderate & $11(39 \%)$ & $25(25 \%)$ & \\
\hline Severe & $3(11 \%)$ & $7(7 \%)$ & \\
\hline PNF & $1(4 \%)$ & $3(3 \%)$ & \\
\hline CMV infection & $6(21 \%)$ & $36(34 \%)$ & 0.15 \\
\hline Acute rejection & $15(54 \%)$ & $66(65 \%)$ & 0.25 \\
\hline Chronic rejection & $2(7 \%)$ & $23(22 \%)$ & 0.06 \\
\hline \multicolumn{4}{|l|}{ Technical complications } \\
\hline Artery thrombosis & - & $5(5 \%)$ & 0.58 \\
\hline Portal thrombosis & - & $3(3 \%)$ & 0.99 \\
\hline Hepatic vein stenosis & - & $1(1 \%)$ & 0.99 \\
\hline Biliary complications & $6(21 \%)$ & $26(25 \%)$ & 0.69 \\
\hline $\begin{array}{l}\text { Renal dysfunction at end } \\
\text { of the } 1 \text { st year }{ }^{\mathrm{a}}\end{array}$ & $14(50 \%)$ & $42(67 \%)$ & 0.21 \\
\hline $\begin{array}{l}\text { Liver dysfunction at end } \\
\text { of the } 1 \text { st year }\end{array}$ & $5(18 \%)$ & $30(45 \%)$ & 0.01 \\
\hline Retransplant & $3(11 \%)$ & $16(15 \%)$ & 0.53 \\
\hline
\end{tabular}

CyA cyclosporine, St steroids, Aza azathioprine, Tac tacrolimus, PNF primary non-function, $C M V$ cytomegalovirus

a Defined as estimated glomerular filtration rate $<60 \mathrm{~mL} / \mathrm{min} /$ $1.73 \mathrm{~m}^{2}$

${ }^{\mathrm{b}}$ Defined as AST/ALT $\geq 100 \mathrm{IU} / \mathrm{L}$ and/or total bilirubin $\geq 1.5$ $\mathrm{mg} / \mathrm{dL}$

survivors was $20-24.3$ years. Of all the 20-year survivors, 2 had died due to hepatitis $C$ recurrence after surviving 21 years. The causes of death in non-20-year survivors are shown in Table 5.

The overall incidence of retransplant in this series was $14 \%$ (19 patients). Among the 20-year survivors, two were retransplanted within the first year post-transplant owing to primary non-function and chronic rejection and a third was retransplanted due to hepatitis $\mathrm{C}$ recurrence after 2 years. Sixteen of the non-20-year survivors were retransplanted: 13 within the first year due to arterial thrombosis [4], chronic rejection [4], primary non-function (3 patients) and acute rejection [2]. The remaining three patients were retransplanted beyond the first year owing to acute rejection [1], chronic rejection [1] and arterial thrombosis [1]. No patients had more than 1 retransplant.
Risk factors of mortality

The univariate analysis of risk factors associated with mortality is shown in Table 6. In multivariate Cox regression analysis, the perioperative variables showing independent predictive value were: HCC indication ( $p=0.049$, OR 1.60), pretransplant renal dysfunction ( $p=0.043$, OR 1.83) and long WIT ( $p=0.016$, OR 1.68). This Cox regression model also showed diabetes mellitus $(p=0.001$, OR 6.03$)$ and liver dysfunction $(p=0.05$, OR 2.29 ) at 1 year as post-transplant variables independently related to long-term survival.

\section{Discussion}

Over two decades have elapsed since LT became accepted as a therapeutic option for end-stage liver disease [1]. During this period, more than 250 centers performing LT have emerged throughout the world and many have reported periodically on their series [2, 3, 14-17] in terms of patient and graft survival; however, little has been reported on the long-term complications of this procedure and the risk factors of late mortality [7-9, 14]. As our transplant program started 25 years ago, we decided to evaluate the outcome of our 20-year survivors in an attempt to understand their morbidity and the main causes of death with a view to developing strategies that may improve the long-term outcome in future series.

For analysis of our results, we should point out that all LT performed between the start of our program in 1988 and 1993 were included. We did not record our experience in pediatric liver transplants, a significant difference compared with other series, and which could explain the lower 20-year LT survival rates in the present analysis $(21 \%)$ versus the $50 \%$ in other studies [2, 5, 7]. Recently, Shoening et al. [9] showed patient and graft survival of 52 and $47 \%$, respectively, at 20 years post-adult LT. However, it should be considered that only $10 \%$ of patients were HCVpositive in their study compared to $34 \%$ in our series.

On analyzing the characteristics of our 20-year survivors, hepatitis $\mathrm{C}$ cirrhosis was the main indication in both groups (36 vs. $34 \%$ in non-20-year survivors), cholestatic cirrhosis was the second leading indication in 20-year survivors $(25 \%)$ and alcoholic cirrhosis $(24 \%)$ followed by HCC ( $22 \%)$, the second and third leading indications in non-20-year survivors. The younger age of donors in that period could explain the unexpected long-term survival from hepatitis $\mathrm{C}$ in 20-year survivors. Moreover, lesser graft steatosis $>20 \%(p=0.06)$, incidence of portal thrombosis $(p=0.05)$ and intraoperative multi-transfusion $(p=0.03)$ were observed in 20-year survivors. These 
Table 4 Evolution over time in 20 year survivors of renal function and liver function, arterial hypertension, diabetes mellitus, dyslipidemia, and immunosuppression $(n=28)$

AST aspartate transaminase, ALT alanine transaminase, $e G F R$ estimated glomerular filtration rate, $C y A$ cyclosporine, St steroids, Tac tacrolimus, $M M F$ mycophenolate mofetil

Table 5 Causes of death in liver transplant patients during the study period

The commonest causes of death in each period since transplant are shown in bold

$H C V$ hepatits $\mathrm{C}$ virus, $H B V$ hepatitis $\mathrm{B}$ virus, $H C C$ hepatocellular carcinoma, PSC primary sclerosing cholangitis

\begin{tabular}{lccccc}
\hline & 1st year & 5th year & 10th year & 15 th year & 20th year \\
\hline Liver function & & & & & \\
AST (IU/L) & $28(10-178)$ & $36(14-160)$ & $39(13-133)$ & $32(14-66)$ & $33(13-135)$ \\
ALT (IU/L) & $38(12-370)$ & $53(10-297)$ & $41(13-205)$ & $41(11-111)$ & $27(11-152)$ \\
Total bilirubin (mg/dL) & $0.9(0.3-2.5)$ & $0.7(0.3-2.2)$ & $0.7(0.4-1.7)$ & $0.7(0.3-2)$ & $0.6(0.3-1.1)$ \\
Renal function & & & & & \\
$($ eGFR mL/min/1.73 m²) & $60(18-96)$ & $60(21-112)$ & $67(12-89)$ & $57(12-98)$ & $64(6-144)$ \\
Arterial hypertension & $12(43 \%)$ & $15(54 \%)$ & $18(64 \%)$ & $17(61 \%)$ & $17(61 \%)$ \\
Diabetes mellitus & $4(14 \%)$ & $4(14 \%)$ & $6(21 \%)$ & $6(21 \%)$ & $6(21 \%)$ \\
Dyslipidemia & $6(21 \%)$ & $7(25 \%)$ & $12(43 \%)$ & $12(43 \%)$ & $12(43 \%)$ \\
Immunosuppression & - & $14(50 \%)$ & $13(46 \%)$ & $11(39 \%)$ & $11(39 \%)$ \\
CyA & $4(14 \%)$ & $7(25 \%)$ & $7(25 \%)$ & $5(18 \%)$ & $4(14 \%)$ \\
Tac & $21(75 \%)$ & $6(21 \%)$ & $1(4 \%)$ & $3(11 \%)$ & $3(11 \%)$ \\
CyA + St/MMF & $3(11 \%)$ & - & $3(11 \%)$ & $6(21 \%)$ & $6(21 \%)$ \\
Tac + St/MMF & - & $1(4 \%)$ & $2(7 \%)$ & - & $1(4 \%)$ \\
Others & - & - & $2(7 \%)$ & $3(11 \%)$ & $3(11 \%)$ \\
Withdrawal & &
\end{tabular}

\begin{tabular}{|c|c|c|c|}
\hline & $\begin{array}{l}<1 \text { year } \\
(n=41,39 \%)\end{array}$ & $\begin{array}{l}1-5 \text { years } \\
(n=41,39 \%)\end{array}$ & $\begin{array}{l}>5 \text { years } \\
(n=22,22 \%)\end{array}$ \\
\hline \multicolumn{4}{|l|}{ Graft-related } \\
\hline \multicolumn{4}{|l|}{ Recurrent primary disease } \\
\hline $\mathrm{HCV}$ & $5(12 \%)$ & $5(12 \%)$ & $5(22 \%)$ \\
\hline $\mathrm{HCC}$ & $1(2 \%)$ & $5(12 \%)$ & $2(9 \%)$ \\
\hline HBV & $1(2 \%)$ & - & - \\
\hline Alcohol & - & - & $1(5 \%)$ \\
\hline PSC & - & $1(2 \%)$ & - \\
\hline \multicolumn{4}{|l|}{ Rejection } \\
\hline Acute & $4(10 \%)$ & $1(2 \%)$ & - \\
\hline Chronic & $4(10 \%)$ & $3(7 \%)$ & $1(5 \%)$ \\
\hline Primary non-function & $3(7 \%)$ & - & - \\
\hline Intraoperative death & $2(5 \%)$ & - & - \\
\hline Arterial thrombosis & $2(5 \%)$ & $4(11 \%)$ & $1(5 \%)$ \\
\hline Biliary complications & $2(5 \%)$ & - & - \\
\hline \multicolumn{4}{|l|}{ Non-graft-related } \\
\hline \multicolumn{4}{|l|}{ Medical complications } \\
\hline Infections & $13(32 \%)$ & $10(25 \%)$ & $1(5 \%)$ \\
\hline Cardiovascular disease & $2(5 \%)$ & $1(2 \%)$ & $5(22 \%)$ \\
\hline Gastrointestinal complications & - & $1(2 \%)$ & - \\
\hline Kidney failure & $2(5 \%)$ & - & - \\
\hline De novo malignancy & - & $8(21 \%)$ & $3(13 \%)$ \\
\hline Accident & - & - & $2(9 \%)$ \\
\hline Others & - & $2(4 \%)$ & $1(5 \%)$ \\
\hline
\end{tabular}

factors had been shown to be associated with worse survival after LT in previous studies [18-20].

Regarding the immediate post-transplant period, CyA was the principal induction immunosuppressive agent in both groups during the transplant era reported here. Although the overall incidence of acute rejection was similar in both groups, it more frequently progressed to chronic rejection in the non-20-year survivors group (22 vs. 
Table 6 Main risk factors associated with overall mortality (Cox regression analyses)
$H C V$ hepatitis $\mathrm{C}$ virus, $H C C$ hepatocellular carcinoma, $C I T$ cold ischemia time, WIT warm ischemia time, $C y A$ cyclosporine, $O R$ odds ratio, $C I$ confidence interval

\begin{tabular}{|c|c|c|c|c|c|c|}
\hline & \multicolumn{3}{|c|}{ Univariate } & \multicolumn{3}{|c|}{ Multivariate } \\
\hline & $p$ & OR & CI $(95 \%)$ & $p$ & OR & CI $(95 \%)$ \\
\hline Recipient age $>60$ years & 0.740 & 1.07 & $0.697-1.663$ & & & \\
\hline Anti-HCV+ & 0.839 & 0.96 & $0.654-1.412$ & & & \\
\hline $\mathrm{HCC}$ & 0.063 & 1.53 & $0.978-2.395$ & 0.049 & 1.60 & $1.002-2.584$ \\
\hline Pretransplant renal dysfunction & 0.030 & 1.90 & $1.064-3.412$ & 0.043 & 1.83 & $1.020-3.292$ \\
\hline Donor age $>40$ years & 0.245 & 0.78 & $0.529-1.177$ & & & \\
\hline Steatosis $>20 \%$ & 0.059 & 0.64 & $0.407-1.017$ & & & \\
\hline Portal thrombosis & 0.268 & 1.32 & $0.804-2.192$ & & & \\
\hline $\mathrm{CIT}>8 \mathrm{~h}$ & 0.301 & 0.81 & $0.552-1.201$ & & & \\
\hline WIT $>60 \mathrm{~min}$ & 0.028 & 1.60 & $1.052-2.444$ & 0.016 & 1.68 & $1.103-2.586$ \\
\hline Severe reperfusion injury & 0.490 & 0.79 & $0.413-1.527$ & & & \\
\hline CyA induction & 0.720 & 1.09 & $0.665-1.805$ & & & \\
\hline \multicolumn{7}{|c|}{ Risk factors associated with long-term survival (after excluding deaths over 1st year post-transplant) } \\
\hline CMV infection & 0.277 & 1.36 & $0.780-2.376$ & & & \\
\hline Acute rejection & 0.171 & 1.45 & $0.852-2.468$ & & & \\
\hline Chronic rejection & 0.005 & 2.26 & $1.289-3.991$ & & & \\
\hline Vascular complications & 0.004 & 3.20 & $1.445-7.103$ & & & \\
\hline Biliary complications & 0.277 & 1.34 & $0.786-2.314$ & & & \\
\hline Retransplant & 0.442 & 1.29 & $0.673-2.480$ & & & \\
\hline Arterial hypertension at 1 year & 0.028 & 2.01 & $1.078-3.765$ & & & \\
\hline Diabetes mellitus at 1 year & 0.001 & 6.94 & $3.131-15.398$ & 0.001 & 6.03 & $2.339-15.574$ \\
\hline Dyslipidemia at 1 year & 0.001 & 3.68 & $1.953-6.934$ & & & \\
\hline Renal dysfunction at 1 year & 0.106 & 1.53 & $0.913-2.573$ & & & \\
\hline Liver dysfunction at 1 year & 0.002 & 2.20 & $1.334-3.643$ & 0.050 & 2.29 & $1.000-5.261$ \\
\hline
\end{tabular}

$7 \%, p=0.06)$, thus reducing patient survival, as reported previously [7, 21, 22]. Consistent immunosuppression levels and avoidance of transition to chronic rejection without increasing the risk of infection have long been critical goals of post-transplant care, mainly during the early years of LT and, therefore, the learning curve in immunosuppression management. Biliary complications are well known to impair both short- and long-term outcomes after LT [2, 3, 7, 23]; however, no significant differences were observed in 20-year survivors compared to non-20-year survivors in our series.

Chronic renal dysfunction is a frequent complication after LT and progresses to end-stage renal disease, requiring hemodialysis in 4-8\% of cases. Sheiner et al. [24] reported that, although follow-up creatinine clearance rates reflected renal insufficiency in 70 patients $(79.5 \%)$, only 4 developed chronic renal failure requiring hemodialysis 5 years after LT. Similar results were reported recently in a Spanish series [14] where more than a third of the patients had chronic renal impairment after 10 years of survival but only $6 \%$ developed end-stage renal failure. These data are confirmed in our long-term survivors: $50 \%$ had renal dysfunction at 1 year post-transplant and $40 \%$ at 20 years with $4 \%$ being on hemodialysis. The renal function stabilization at the end of follow-up reflects the less immunosuppression required or even switched to other proven less nephrotoxic immunosuppressors such as mammalian Target of Rapamycin (mTOR) inhibitors or mycophenolate mofetil in monotherapy [25-30].

Arterial hypertension, diabetes mellitus and dyslipidemia were the most common medical complications in our 20-year survivors, and their prevalence increased throughout follow-up, reaching 61, 21 and $43 \%$, respectively. These results are comparable to those published in the literature [8, 9, 14, 24, 31, 32]. Moreover, Rubin et al. [14] recently estimated that the prevalence of arterial hypertension, diabetes mellitus and dyslipidemia in LT recipients at 10 years post-transplant was increased twofold compared to the general population. Close surveillance to treat promptly these events is required; moreover, better management of immunosuppressive drugs will be reflected in a lower incidence of metabolic complications in future series [33-36].

The incidence of de novo tumors in our 20-year survivors was $25 \%$, higher than that published in the literature [9, 14] and mainly due to skin cancer which is more prevalent in Mediterranean areas, and even higher than that observed in the general population [37-39]. For this reason, 
long-term screening protocols for skin tumors should be mandatory in LT patients.

The main cause of death in our non-20-year survivors was infections (32\%) in the first year and between 1 and 5 years post-transplant $(25 \%)$. These data are consistent with findings in other cohorts [2, 40, 41], as recently reported by Schoening et al. [9], who showed that $21 \%$ of deaths attributed to early or late infections occurred more often during the first year post-transplant. Once again, no doubts existed as to the cause-effect of over-immunosuppression during the first era of LT programs. Schoening et al. [9] also reported de novo tumors as the main cause of death within the second decade post-LT (26\%), whereas it was the second cause of death $(21 \%)$ in our study. This could be explained by the different etiologies for LT in each group, if we consider that alcohol-induced cirrhosis, strongly related to neoplastic diseases, was the first indication for LT in the German group, and hepatitis $\mathrm{C}$ in our series. In view of this, hepatitis $\mathrm{C}$ recurrence was the main cause of death (22\%) together with cardiovascular disease (22\%) in the last years of follow-up, as expected due to the long-term follow-up-related nature and similar to results reported by other groups [42, 43].

Regarding risk factors of mortality, recent papers [2, 3, 7, 9] have described recipient age and gender, urgent indication, HCC, CIT, retransplant and biliary complications as major variables affecting long-term survival. Interestingly, recipient age or gender did not affect survival in this study, even considering that our cohort was older than those described in the literature. The only determinant pretransplant factors for long-term survival in our series were $\mathrm{HCC}$ and renal dysfunction, owing to the malignant nature of the former and as a symptom of pre-transplant recipient "poor status" in the latter, as historically reported [4, 4446]. The low median age of our grafts at that time could have neutralized the CIT effect in our results. However, longer WIT proved to be an independent risk factor, as Busuttill et al. [3] had already demonstrated. With respect to post-transplant variables, liver dysfunction and diabetes mellitus at the end of the first year post-transplant were significant independent risk factors of mortality. This would appear to be normal considering that a graft, which after 1 year of survival is not able to function correctly mainly because of $\mathrm{HCV}$ recurrence and acute rejection, is less likely to survive in the long-term. Diabetes mellitus has also been linked to hepatitis $\mathrm{C}$ recurrence and described as one of the major cardiovascular risk factors, two powerful reasons that explained our results [35, 47, 48].

In conclusion, our study adds more information on outcome in LT after 20 years of follow-up, taking into account the cumulative experience acquired since our program started in the late 1980s, the different technical approach, the aggressive immunosuppression protocols used and even that one-third of our recipients were hepatitis C-positive. Although LT offers acceptable long-term survival, the significant comorbidities presented by recipients (arterial hypertension, diabetes mellitus, dyslipidemia, de novo tumor, hepatitis $\mathrm{C}$ recurrence) oblige us to adopt early prevention and therapeutic measures and modify the management of immunosuppression to minimize long-term morbidity and improve long-term survival. However, if prolonged life is expected in our LT patients and considering the current changes in immunosuppression (no steroids, calcineurin inhibitors minimization, mTOR inhibitors), type of donors (expanded criteria, living donors) and the new antiviral therapies, further studies will be be required in coming years to reassess long-term outcome.

Acknowledgements The authors thank Christine O'Hara for English language editing and Esther Delgado for secretarial work.

Compliance with ethical standards and Conflict of interest C. Dopazo, I. Bilbao, Ll. Castells, G. Sapisochin, C. Moreiras, I. Campos-Varela, J. Echeverri, M. Caralt, JL. Lázaro, and R. Charco declare that they have not conflict of interest.

\section{References}

1. National Institutes of Health Consensus Development Conference Statement. Liver transplantation-June 20-23, 1983. Hepatology 1984;4:107S-110S

2. Jain A, Reyes J, Kashyap R, Doson SF, Demetris AJ, Ruppert K, et al. Long-term survival after liver transplantation in 4000 consecutive patients at a single center. Ann Surg 2000;232:490-500

3. Busuttill RW, Farmer DG, Yersiz H, Hiatt JR, McDiarmid SV, Goldstein LI, et al. Analysis of long-term outcomes of 3200 liver transplantations over two decades: a single-center experience. Ann Surg 2005;241:905-916

4. Bilbao I, Armadans L, Lazaro JL, Hidalgo E, Castells L, Margarit C. Predictive factors for early mortality following liver transplantation. Clin Transplant 2003;17:401-411

5. Adam R, Karam V, Delvart V, ÓGrady J, Mirza D, Klempnauer $\mathrm{J}$, et al. Evolution of indications and results of liver transplantation in Europe. A report from the European Liver Transplant Registry (ELTR). J Hepatol 2012;57:675-688

6. American Liver Transplant Registry, OTN/SRTR 2011. Annual Report. http://www.srtr.org

7. Duffy JP, Kao K, Ko CY, Farmer DG, McDiarmid SV, Hing JC, et al. Long-term patient outcome and quality of life after liver transplantation. Analysis of 20-year survivors. Ann Surg 2010;252:652-661

8. Jain A, Singhal A, Fontes P, Mazariegos G, DeVera ME, Cacciarelli $\mathrm{T}$, et al. One thousand consecutive primary liver transplants under tacrolimus immunosuppression: a 17- to 20-year longitudinal follow-up. Transplantation 2011;91:1025-1030

9. Schoening WN, Buescher N, Rademacher S, Andreou A, Kuehn $\mathrm{S}$, Neuhaus R, et al. Twenty-year longitudinal follow-up after orthotopic liver transplantation: a single-center experience of 313 consecutive cases. Am J Transplant 2013;13:2384-2394

10. Demetris A, Batts K, Dhillon A, Ferrell L, Fung J, Geller SA. Banff schema for grading liver allograft rejection: an international consensus document. Hepatology 1997;25:658-663 
11. Levey AS, Coresh J, Balk E, Kausz AT, Levin A, Steffes MW, et al. National Kidney Foundation practice guidelines for chronic kidney disease: evaluation, classification, and stratification. Ann Intern Med 2003;139:137-147

12. European Society of Hypertension-European Society of Cardiology guidelines for the management of arterial hypertension. J Hypertens 2003;21:1011-1053

13. World Health Organization. Definition and Diagnosis of Diabetes Mellitus and Intermediate Hyperglycemia: Report of a WHO/IDF Consultation. Geneva: World Health Organization, 2006. ISBN 9789241594936

14. Rubin A, Sánchez-Montes C, Aguilera V, Juan FS, Ferrer I, Moya A, et al. Long-term outcome of "long-term liver transplant survivors". Transpl Int 2013;26:740-750

15. Ciccarelli O, Kaczmarek B, Roggen F, DeReyck C, Goffette P, Danse E, et al. Long-term medical complications and quality of life in adult recipients surviving 10 years or more after liver transplantation. Acta Gastroenterol Belg 2005;68:323-330

16. Pfitzmann R, Nussler NC, Hippler-Benscheidt M, Neuhaus R, Neuhaus P. Long-term results after liver transplantation. Transpl Int 2008;21:234-246

17. Aberg $\mathrm{F}$, Isoniemi $\mathrm{H}$, Hockerstedt $\mathrm{K}$. Long-term results of liver transplantation. Scand J Surg 2011;100:14-21

18. Briceño J, Ciria R, Pleguezuelo M, de la Mata M, Muntané J, Naranjo A, et al. Impact of donor graft steatosis on overall outcome and viral recurrence after liver transplantation for hepatitis C virus cirrhosis. Liver Transpl 2009;15:37-48

19. Rodríguez-Castro KI, Porte RJ, Nadal E, Germani G, Burra P, Senzolo M, et al. Management of nonneoplastic portal vein thrombosis in the setting of liver transplantation: a systematic review. Transplantation 2012;94:1145-1153

20. Rana A, Petrowsky H, Hong JC, Agopian VG, Kaldas FM, Farmer D, et al. Blood transfusion requirement during liver transplantation is an important risk factor for mortality. J Am Coll Surg 2013;216:902-907

21. Blakolmer K, Jain A, Ruppert K, Gray E, Duquesnoy R, Murase $\mathrm{N}$, et al. Chronic liver allograft rejection in a population treated primarily with tacrolimus as baseline immunosuppression: longterm follow-up and evaluation of features for histopathological staging. Transplantation 2000;69:2330-2336

22. Uemura T, Ikegami T, Sánchez EQ, Jennings LW, Narasimhan G, McKenna GJ, et al. Late acute rejection after liver transplantation impacts patient survival. Clin Transplant 2008;22: 316-323

23. Enestvedt CK, Malik S, Reese PP, Maskin A, Yoo PS, Fayek SA, et al. Biliary complications adversely affect patient and graft survival after liver retransplantation. Liver Transpl 2013;19: 965-972

24. Sheiner PA, Magliocca JF, Bodian CA, Kim-Schluger L, Altaca $\mathrm{G}$, Guarrera JV, et al. Long-term medical complications in patients surviving $\geq 5$ years after liver transplant. Transplantation 2000;69:781-789

25. Barckmann A, Nashan B, Schmidt HH, Böker KH, Emmanouilidis N, Rosenau J, et al. Improvement of acute and chronic renal dysfunction in liver transplant patients after substitution of calcineurin inhibitors by mycophenolate mofetil. Transplantation 2000;69:1886-1890

26. Kamphues C, Bova R, Rocken C, Neuhaus R, Pratschke J, Neuhaus $\mathrm{P}$, et al. Safety of mycophenolate mofetil monotherapy in patients after liver transplantation. Ann Transplant 2009;14:40-46

27. Bilbao I, Castells L, Rojas L, Cancino J, Dopazo C, Castro E, et al. Immunosuppression based on mycophenolate mofetil in stable liver transplanted patients. Int Immunopharmacol 2006;6: 1977-1983
28. DeSimone P, Nevens F, De Carlis L, Metselaar HJ, Beckebaum $\mathrm{S}$, Saliba F, et al. Everolimus with reduced tacrolimus improves renal function in de novo liver transplant recipients: a randomized controlled trial. Am J Transplant 2012;12:3008-3020

29. Abdelmalek MF, Humar A, Stickel F, Andreone P, Pascher A, Barroso E, et al. Sirolimus conversion regimen versus continued calcineurin inhibitors in liver allograft recipients: a randomized trial. Am J Transplant 2012;12:694-705

30. Bilbao I, Sapisochin G, Dopazo C, Lazaro JL, Pou L, Castells L, et al. Indications and management of everolimus after liver transplantation. Transplant Proc 2009;41:2172-2176

31. Charco R, Cantarell C, Vargas V, Capdevila L, Lázaro JL, Hidalgo E, et al. Serum cholesterol changes in long-term survivors of liver transplantation: a comparison between cyclosporine and tacrolimus therapy. Liver Transpl 1999;5:204-208

32. Moon JI, Barbeito R, Faradji RN, Gaynor JJ, Tzakis AG. Negative impact of new-onset diabetes mellitus on patient and graft survival after liver transplantation: long-term follow-up. Transplantation 2006;82:1625-1628

33. Charco R, Bilbao I, Chavez R, Castells LI, Hidalgo E, Margarit C. Low incidence of hypercholesterolemia among liver transplant patients under tacrolimus monotherapy immunosuppression. Transplant Proc 2002;34:1555-1556

34. Desai S, Hong JC, Saab S. Cardiovascular risk factors following orthotopic liver transplantation: predisposing factors, incidence and management. Liver Int 2010;30:948-957

35. Becker T, Foltys D, Bilbao I, D'Amico D, Colledan M, Bernar$\operatorname{dos} \mathrm{A}$, et al. Patient outcomes in two steroid-free regimens using tacrolimus monotherapy after daclizumab induction and tacrolimus with mycophenolate mofetil in liver transplantation. Transplantation 2008;86:1689-1694

36. Weiler N, Thrun I, Hoppe-Lotichius M, Zimmermann T, Kraemer I, Otto G. Early steroid-free immunosuppression with FK506 after liver transplantation: long-term results of a prospectively randomized double-blinded trial. Transplantation 2010;90:1562-1566

37. Aberg F, Pukkala E, Hockerstedt K, Sankila R, Isoniemi H. Risk of malignant neoplasms after liver transplantation: a populationbased study. Liver Transpl 2008;14:1428-1436

38. Herrero JL. De novo malignancies following liver transplantations: impact and recommendations. Liver Transpl 2009;15(Suppl 2):S90-S94

39. Sapisochin G, Bilbao I, Dopazo C, Castells L, Lázaro JL, Rodríguez $\mathrm{R}$, et al. Evolution and management of de novo neoplasm post-liver transplantation: a 20-year experience from a single European centre. Hepatol Int 2011;5:707-715

40. Asfar S, Metrakos P, Fryer J, Verran D, Ghent C, Grant D, et al. An analysis of late deaths after liver transplantation. Transplantation 1996;61:1377-1381

41. Pfitzmann R. Nussler NC, Hippler-Benscheidt M, Neuhaus R, Neuhaus P Long-term results after liver transplantation. Transpl Int 2008;21:234-246

42. Rabkin JM, de la Melena V, Orloff SL, Corless CL, Rosen HR, Olyaei AJ. Late mortality after orthotopic liver transplantation. Am J Surg 2001;181:475-479

43. Vogt DP, Henderson M, Carey WD, Barnes D. The long-term survival and causes of death in patients who survive at least 1 year after liver transplantation. Surgery 2002;132:775-780

44. Nair S, Verma S, Thuluvath PJ. Pre-transplant renal function predicts survival in patients undergoing orthotopic liver transplantation. Hepatology 2002;35:1179-1185

45. Burra P, Senzolo M, Masier A, Prestele H, Jones R, Samuel D, et al. Factors influencing renal function after liver transplantation. Results from the MOST, an international observational study. Dig Liver Dis 2009;41:350-356 
46. Bilbao I, Charco R, Balsells J, Lazaro JL, Hidalgo E, Llopart L, et al. Risk factors for acute renal failure requiring dialysis after liver transplantation. Clin Transplant 1998;12:123-129

47. Moon JI, Barbeito R, Faradji RN, Gaynor JJ, Tzakis AG. Negative impact of new-onset diabetes mellitus on patient and graft survival after liver transplantation: long-term follow-up. Transplantation 2006;82:1625-1628
48. Sarno G, Mentha RJ, Guardado-Mendoza R, Jimenez-Ceja LM, De Rosa P, Muscogiuri G. New-onset diabetes mellitus: predictive factors and impact on the outcome of patients undergoing liver transplantation. Curr Diabetes Rev 2013;9:78-85 